\title{
Who needs patient satisfaction surveys? Perspectives of Polish doctors, nurses, and patients
}

\begin{abstract}
Introduction. Patient satisfaction surveys are still popular tools for obtaining feedback on the quality of health care. Nonetheless, there is a paucity of data to indicate whether health care providers even want patients to assess the quality of care delivered. Neither it is certain whether patients are interested in participating in such surveys.

Aim. To present and compare the perspectives of doctors, nurses, and patients on the validity of health care customer satisfaction surveys.

Material and methods. A cross-sectional survey design was used. The questionnaires were administered to doctors, nurses and patients in three hospitals of different sizes (small, medium, and large), all in the north-east of Poland. Each sample group was given 200 questionnaires; responses were received from 95 doctors (47.5\%), 190 nurses (95\%), and 182 patients $(91 \%)$, and included in the final analyses.

Results. Most respondents (doctors $-64.2 \%$; nurses $-61.6 \%$; patients $-87.4 \%$ ) answered 'Yes' to the question 'Do you think that patients should evaluate the quality of health care?' Analysis of data allowed to identify the following main reasons why patients should evaluate the quality of health care: 1 . to enhance the quality of care; 2 . to recognise patients as evaluators; 3 . to motivate providers to work more efficiently; and 4. to emphasise the impact of evaluation on a core value, i.e. health. Doctors and nurses outlined reasons why they did not advocate conducting patient satisfaction surveys: satisfaction surveys are redundant; negative evaluations; unwillingness to be evaluated by patients; satisfaction surveys hamper effective work with patients; surveys are not objective; survey results are not communicated to providers.

Conclusions. Patient satisfaction surveys are desirable tools for evaluating the quality of health care delivery despite the fact that they frequently raise concerns amongst providers and patients. There is, therefore, a definite need for providers to experience the benefits of measuring patient satisfaction. Another important practical implication is that patients need to be convinced that their opinions do matter and contribute to improving the quality of services.
\end{abstract}

Keywords: patient satisfaction, questionnaires, patients, nurses, physicians.

DOI: $10.1515 /$ pjph-2015-0027

\section{INTRODUCTION}

Both medical providers and patients are concerned about the quality of health care. Therefore, surveying representatives of the two parties is one of the procedures which may be used for assessing the quality of health care services [1]. Notwithstanding the fact that surveys are sometimes approached with uncertainty and apprehension, patient satisfaction surveys are still popular tools for obtaining feedback on the quality of health care [2,3]. In the United Kingdom, for example, there is a strong tradition of using patient satisfaction surveys to examine different contexts of health care [4]. In the countries of Central and Eastern Europe, however, measuring patient satisfaction began to interest medical providers in the 1990s and coincided with the introduction of health care reforms [5-8].

Patients' feedback may be used in various ways to improve the quality of health care services offered by providers [5-9]. Nonetheless, there is a paucity of data to indicate whether health care providers even want patients to assess the quality of care delivered. Neither it is certain whether patients are interested in participating in such surveys.

\section{AIM}

The aim of this work is to present and compare the perspectives of doctors, nurses, and patients on the validity of health care customer satisfaction surveys.

\footnotetext{
${ }^{1}$ Department of Family Medicine and Community Nursing, Medical University of Bialystok, Poland

${ }^{2}$ Department of Surgery Nursing, Medical University of Bialystok, Poland

${ }^{3}$ Department of Foreign Languages, Medical University of Bialystok, Poland

${ }^{4}$ Institute of Healthcare, Edward F. Szczepanik Higher Vocational School in Suwalki, Poland
} 


\section{MATERIAL AND METHODS}

A questionnaire-based survey was conducted amongst doctors, nurses, and patients. The sample included three hospitals of different sizes (small, medium, and large), all in the north-east of Poland. In each hospital, the questionnaires were administered in surgical wards and internal medicine wards to all doctors and nurses employed at the time and to all hospitalised patients whose condition did not preclude them from completing the survey. Each sample group (doctor, nurse, patient) was given 200 questionnaires; there were 95 responses from doctors $(47.5 \%), 190$ from nurses $(95 \%)$, and 182 from patients $(91 \%)$, all of which were included in the final analyses. The survey was conducted in 2012. Table 1 presents background characteristics of the respondents.

TABLE 1. Characteristics of respondents.

\begin{tabular}{|c|c|c|c|}
\hline \multirow{2}{*}{ Characteristic } & Doctors & Nurses & Patients \\
\hline & $\mathrm{N}=95(100 \%)$ & $190(100 \%)$ & $182(100 \%)$ \\
\hline \multicolumn{4}{|l|}{ Age (years) } \\
\hline$\leq 30$ & $20(21.0)$ & $11(5.8)$ & $11(6.1)$ \\
\hline $31-40$ & $29(30.5)$ & $54(28.4)$ & $35(19.2)$ \\
\hline $41-60$ & $43(45.3)$ & $125(65.8)$ & $85(46.7)$ \\
\hline$>60$ & $3(3.2)$ & - & $51(28.0)$ \\
\hline \multicolumn{4}{|l|}{ Sex } \\
\hline Women & $59(62.1)$ & $190(100.0)$ & $111(61.0)$ \\
\hline Men & $36(37.9)$ & - & $71(39.0)$ \\
\hline \multicolumn{4}{|l|}{ Education } \\
\hline Elementary & - & - & $29(15.9)$ \\
\hline Technical & - & - & $39(21.4)$ \\
\hline Secondary & - & $92(48.4)$ & $72(39.6)$ \\
\hline $\begin{array}{c}\text { College } \\
\text { /University }\end{array}$ & $95(100.0)$ & $98(51.6)$ & $42(23.1)$ \\
\hline \multicolumn{4}{|c|}{ Years worked in health care } \\
\hline$<5$ & $24(25.3)$ & $12(6.3)$ & - \\
\hline $5-10$ & $14(14.7)$ & $21(11.1)$ & - \\
\hline $11-20$ & $31(32.6)$ & $52(27.4)$ & - \\
\hline $21-30$ & $13(13.7)$ & $92(48.4)$ & - \\
\hline$>30$ & $13(13.7)$ & $13(6.8)$ & - \\
\hline \multicolumn{4}{|l|}{ Specialty training } \\
\hline Yes & $51(53.7)$ & 46 & - \\
\hline No & $44(46.3)$ & 91 & - \\
\hline
\end{tabular}

The questionnaire consisted of both open and closed questions and background characteristics. As suggested by research methodologists, open questions following closed questions are useful for clarifying the reasons and explanations [10]. The following questions were asked of the respondents (response options, when present, are listed in parentheses):

1. Do you think that patients should evaluate the quality of health care? (Yes/No/It's hard to say);

2. Could you justify your answer, please?

3. Would you like patient satisfaction surveys to be conducted in the ward? (Yes/No/It's hard to say) - in questionnaires for doctors and nurses or Would you like to participate in patient satisfaction surveys? (Yes/No/It's hard to say) in questionnaires for patients;

4. Could you justify your answer, please?

The data collected was coded for statistical analysis with Statistica PL v.10 software. The chi-square test was used to compare responses to closed questions. The level of statistical significance was set at $\mathrm{P}<0.05$. All responses to open questions were entered into a text file, thematically analysed and coded [11].

\section{RESULTS}

Most respondents answered "Yes" to the question "Do you think that patients should evaluate the quality of health care?". However, the affirmative response was most frequent amongst patients (87.4\%) and least frequent amongst nurses (61.6\%) (Table 2). The results demonstrated a statistically significant difference between the sample groups $\left(\mathrm{chi}^{2}=34.952 ; \mathrm{p}<0.0001\right)$.

TABLE 2. Distribution of responses to the question 'Do you think that patients should evaluate the quality of health care?'

\begin{tabular}{|c|c|c|c|}
\hline & Doctors & Nurses & Patients \\
\hline Kesponse & $n=95(100 \%)$ & $n=190(100 \%)$ & $n=182(100 \%)$ \\
\hline Yes & $61(64.2)$ & 117 (61.6) & $159(87.4)$ \\
\hline No & $14(14.7)$ & $26(13.7)$ & $8(4.4)$ \\
\hline It's hard to say & $20(21.1)$ & $47(24.7)$ & $15(8.2)$ \\
\hline
\end{tabular}

\section{Why patients should evaluate the quality of health care}

The following main reasons were identified as to why patients should participate in evaluating the quality of health care: (1) to enhance the quality of care; (2) to recognise patients as evaluators; (3) to motivate providers to work more efficiently; and (4) to emphasise the impact of evaluation on a core value, i.e. health (Table 3 ).

TABLE 3. Reasons why patients should evaluate the quality of health care.

\begin{tabular}{|c|c|c|c|}
\hline \multirow{2}{*}{ Response } & Doctors & Nurses & Patients \\
\hline & $n=61(100 \%)$ & $n=117(100 \%)$ & $n=159(100 \%)$ \\
\hline $\begin{array}{l}\text { Enhancement } \\
\text { of health care } \\
\text { quality }\end{array}$ & $32(52.4)$ & $60(51.0)$ & $65(40.9)$ \\
\hline $\begin{array}{l}\text { Recognition of } \\
\text { patients as care } \\
\text { evaluators }\end{array}$ & $18(29.4)$ & $21(17.9)$ & $58(36.5)$ \\
\hline $\begin{array}{l}\text { Motivation } \\
\text { to work more } \\
\text { efficiently }\end{array}$ & $4(6.5)$ & $18(15.0)$ & - \\
\hline $\begin{array}{l}\text { Matter concern- } \\
\text { ing a core value, } \\
\text { i.e. health }\end{array}$ & - & $6(5.0)$ & $10(6.3)$ \\
\hline Other & $1(1.6)$ & $6(5.0)$ & $10(6.3)$ \\
\hline $\begin{array}{l}\text { No reason } \\
\text { provided }\end{array}$ & $4(6.5)$ & $4(3.0)$ & $11(6.9)$ \\
\hline
\end{tabular}




\subsection{Enhancement of health care quality}

When justifying their belief that patients should evaluate the quality of health care, respondents most frequently stated that it serves to enhance the quality of care. Presented below is a synthesis of key points from respondents' answers.

"Feedback from patients is necessary to maintain the correct level of health care quality. Patients evaluate the quality of care delivered to them most objectively and it is patients who value good quality of health care most." (Doctor, questionnaire 14)

Some respondents perceived patients as partners in the health care process: "[patients] stimulate medical personnel to improve the quality of services, prevent or reduce the risk of medical error and malpractice." (Nurse, questionnaire 5)

"Patients should evaluate the quality of health care so that medical personnel are aware of patients' opinions and improve the quality of their work." (Patient, questionnaire 19)

\subsection{Recognition of patients as care evaluators}

Respondents from all three groups (predominantly patients) claimed that patients were entitled to evaluate the quality of health care. The following paragraphs include sample answers from doctors and nurses.

"It is the patient who is under our care. Health care would not exist without patients and this is why they, as the focus of our work, have the right to expect the best care possible." (Doctor, questionnaire 91)

"Patients matter most to nurses and doctors in the treatment process and I think that they should have their say about the quality of health care." (Nurse, questionnaire 90)

Patients, however, justified their responses in various ways and presented different reasons to explicate their belief that they should be involved in evaluating health care quality. Some of them claimed that they paid premiums and were entitled to evaluate the care that they received.

"Patients should be provided with the best standards of care because they pay monthly premiums. Consequently, they should be able to provide input into the evaluation of care and the change of provider when they experience inconvenience." (Patient, questionnaire 5)

Other patients pointed to the domains the evaluation investigated and suggested that the patient should assess the doctor-patient relationship rather than evaluate medical procedures.

'Patients are under doctors' and nurses' care and this is what they have most to say about. Thus, patients should not evaluate procedures; instead they should assess the doctors' and nurses' approach to patient care and their level of commitment." (Patient, questionnaire 21)

Another group of patients emphasized the significance of their role in the evaluation of health care quality.

"Being able to evaluate the quality of health care allows patients to express their opinions about the people caring for them. Our views are respected thanks to such surveys." (Patient, questionnaire 15)

\subsection{Motivation to work more efficiently}

Respondents also suggested that patient satisfaction surveys may serve to motivate doctors and nurses to work more efficiently.
"They will be motivated to upgrade their qualifications in order to improve work performance." (Nurse, questionnaire 131)

"Personnel evaluation enhances work efficiency." (Doctor, questionnaire 72)

\subsection{Matter concerning a core value, i.e. health}

Both providers and patients emphasized the impact of satisfaction surveys on a core value, i.e. health (Table 3 ).

"Patients should be able to evaluate the quality of health care because they trust doctors and nurses with their lives and health." (Nurse, questionnaire 44)

"Patients should evaluate health care quality because it comprises activities aimed at improving health behaviors and health is a value of the highest priority." (Patient, questionnaire 2)

\section{Reasons why patients should not evaluate health care quality}

A substantially smaller proportion of the study participants asserted that patients should not evaluate the quality of care. The percentage distribution of respondents opposing patient satisfaction surveys was as follows: $14.7 \%$ of doctors, $13.7 \%$ of nurses, and $4.4 \%$ of patients. The following three reasons against measuring satisfaction with health care were provided: patients possess inadequate knowledge of medicine, patients are too demanding and litigious, surveys conducted amongst patients do not change anything.

\subsection{Inadequate medical knowledge}

The most commonly cited reason why patients should not evaluate health care quality was their inadequate medical knowledge. Presented below is a synthesis of key issues emerging from respondents' answers.

"Patients should not evaluate the quality of care because they have many rights anyway and they often have inadequate knowledge of health care." (Doctor, questionnaire 42)

"[Such] evaluation will not be credible. Only patients with medical background may evaluate health care quality and expertise. Patients can only say if I am nice and smile; they cannot evaluate the quality and professionalism of my work, which is what matters most." (Nurse, questionnaire 31)

\subsection{Patients are too demanding and litigious}

Both doctors and nurses claimed that patients were sometimes too demanding and litigious and they sometimes complained without any reason. However, both parties acknowledged that satisfaction surveys conducted amongst patients could be a factor contributing to quality improvement.

"Complaining is 'trendy' - complaining about everything and everyone. Unbelievable!” (Nurse, questionnaire 74)

"Patients often have heightened expectations and they do not know anything about the organisation of health care and they evaluate doctors' and nurses' work critically in terms of fulfilling patients' wishes. However, sometimes some patients' comments may help to improve the organisation of work in the ward." (Doctor, questionnaire 33)

Furthermore, some respondents concluded that conducting patient satisfaction surveys could result in a complete lack of respect for doctors. 
"It leads to a complete lack of respect for doctors and their work. Patients nowadays have no obligations, such as taking care of their health, complying with treatment plans, behaving courteously; instead they only have rights. They have rights to everything - 'I pay and I demand'." (Doctor, questionnaire 50)

It was also suggested that evaluation of health care could reflect patients' dissatisfaction with diagnosis.

"On the one hand, evaluation would enhance the quality of health care, but on the other, there are many patients unhappy with their diagnoses, not with medical care. This results in a negative attitude towards medical personnel." (Doctor, questionnaire 66)

\subsection{Surveys conducted amongst patients do not change anything}

A different group of respondents suggested that patient satisfaction surveys did not change anything and yielded no significant results. Furthermore, they argued that conducting such surveys could have negative implications for the provider-patient relationship.

"Patient satisfaction surveys are redundant, as they would not have significant influence on the quality of health care as a whole. They could only destroy the doctor-patient relationship." (Doctor, questionnaire 32)

\section{Participation in patient satisfaction surveys}

When responding to the second closed question, 'Would you like to take part in patient satisfaction surveys?', the vast majority of respondents chose the 'Yes' answer. However, the proportions of positive responses in the sample groups were different. Only slightly more than half of the patients $(53.3 \%)$ declared that they would like to participate in such surveys. Almost every third patient stated that he/she would not like to partake in satisfaction surveys. The frequency of positive answers was greater amongst doctors (63.1\%) and nurses $(58.9 \%)$. The results demonstrated a statistically significant difference between the sample groups of nurses and patients $\left(\mathrm{chi}^{2}=6.825 ; \mathrm{p}=0.0329\right)$ (Table 4). Patients who declared that they would not like to participate in satisfaction surveys $(n=57 ; 31.3 \%)$ presented the following rationale:

- I have no time or willingness and I do not feel like it,

- I hardly ever use health care services, surveys do not change anything,

- I do not like evaluating other people,

- I am concerned about the consequences.

TABLE 4. Distribution of responses to the question 'Would you like patient satisfaction surveys to be conducted in the ward?' - in questionnaires for doctors and nurses/'Would you like to participate in patient satisfaction surveys?' - in questionnaires for patients.

\begin{tabular}{|c|c|c|c|}
\hline \multirow{2}{*}{ Response } & Doctors & Nurses & Patients \\
\hline & $n=95(100 \%)$ & $n=190(100 \%)$ & $n=182(100 \%)$ \\
\hline Yes & $60(63.1)$ & $112(58.9)$ & $97(53.3)$ \\
\hline No & $20(21.1)$ & $38(20.0)$ & $57(31.3)$ \\
\hline It's hard to say & $15(15.8)$ & $40(21.1)$ & $28(15.4)$ \\
\hline
\end{tabular}

The following response provided by one of the health care consumers is highly significant because the patient recognises the possibility of providing a critical evaluation, whilst expressing concerns about the lack of anonymity and, consequently, about being treated unjustly by providers:

"If I expressed criticism of a particular health care institution and the survey were not anonymous, I would fear being treated worse by providers in consequence." (Patient, questionnaire 66)

Doctors and nurses outlined similar reasons why they did not advocate conducting patient satisfaction surveys in the ward (Table 5).

TABLE 5. Reasons and examples provided by doctors and nurses.

\begin{tabular}{lc}
\hline \multicolumn{1}{c}{ Reasoning } & Examples provided by doctors and nurses \\
"All doctors, in accordance with the ethical \\
framework of their profession, perform their work \\
to the best of their abilities and according \\
to the newest guidelines. A hospital is an institution \\
providing medical care, not a spa resort, \\
and high standards of health care are vital \\
redundant \\
and as such reflect patients' satisfaction." \\
(Doctor, questionnaire 50)
\end{tabular}

Some respondents suggested alternative solutions, such as combining patient satisfaction surveys with employee satisfaction surveys:

"When introducing patient satisfaction surveys, one should consider introducing employee satisfaction surveys and incentives for staff to work efficiently (for example financial benefits, sabbaticals), create working conditions and provide equipment as well as enough personnel for the provision of good quality of care." (Nurse, questionnaire 31)

\section{DISCUSSION}

To the best of authors' knowledege, the findings of the study are unique since no researchers have ever looked into patient satisfaction surveys. One of the advantages of our research is presenting providers' perspectives, including their concerns, on patient satisfaction. Nevertheless, a number of limitations need to be noted regarding this small-scale study. First of all, it was conducted in only three hospitals, although they were diverse in terms of size and services they provided. Secondly, participation in the study was voluntary 
and the beliefs held by those who refused to complete the questionnaire are unknown. Thirdly, not all respondents provided answers to the open questions and, therefore, they did not provide data for analysis. The sampling may cause some reservations, as the approach we have adopted does not guarantee representativeness of the generated results. However, it is not possible to verify that all the reasons why patients should evaluate the quality of health care have been identified. Neither can we verify why healthcare providers and patients themselves do not want to participate in patient satisfaction surveys. Nevertheless, the amount of questionnaires returned was sufficient to develop statistical data. The respondents' written feedback was relatively clear and specific and did not raise any interpretative doubts. Qualitative data, e.g in-depth interviews with providers and patients could provide more comprehensive data.

The role of patients as evaluators, which has been comprehensively discussed in the literature $[4,12,13]$ was also acknowledged in the present study. The following providers' concerns about being evaluated by patients were expressed:

- patients lack sufficient medical knowledge to evaluate health care,

- some patients' expectations are heightened and unrealistic of health services,

- patients have too many rights and few obligations,

- complaining is generally regarded as 'trendy',

- providers may also evaluate care quality critically.

Davies and Cleary [13] conducted semi-structured interviews with key informants to identify factors affecting the use of patient survey data in quality improvement. They identified organisational barriers (e.g. a traditional hierarchical management structure), professional barriers (e.g. the sceptical responses of staff to survey results) and data-related barriers (e.g. the long interval from data collection to analysis and feedback).

Although most patients in this study concluded that they should evaluate care quality, nearly every third patient in the sample replied negatively to the following survey question: 'Would you like to participate in patient satisfaction surveys?' The most commonly quoted reasons for not being too eager to evaluate care quality included lack of time, infrequent use of health services, and concerns about expressing negative opinions which would later have negative implications for the medical care process. All the aforementioned results should be taken into account whilst designing patient satisfaction surveys.

\section{Practical implications}

The empirical findings of this study provide the following set of practical implications for the design and use of patient satisfaction surveys:

- satisfaction surveys must provide a guarantee of respondent anonymity;

- survey findings should be communicated to all relevant stakeholders;

- personnel should have a clear understanding of survey objectives;

- patient satisfaction surveys may be conducted alongside personnel satisfaction surveys;

- every effort should be made to minimize providers' concerns about being evaluated by patients.

\section{CONCLUSION}

Patient satisfaction surveys are desirable tools for evaluating the quality of health care delivery despite the fact that they frequently raise concerns amongst providers and patients. There is, therefore, a definite need for providers to experience the benefits of measuring patient satisfaction. Another important practical implication is that patients need to be convinced that their opinions do matter and contribute to improving the quality of services.

\section{REFERENCES}

1. Donabedian A. Edited by Rashid Bashshur. An Introduction to Quality Assurance in Health Care. Oxford: Oxford University Press; 2003.

2. Kmietowicz Z. Patients don't understand question often used to measure satisfaction in NHS. Brit Med J. 2012;344:e4242.

3. Teijlingen van ER. Theoretical foundation needed. Brit Med J. 2010;341:c6319.

4. Fitzpatrick R. Scope and measurement of patient satisfaction. In: R. Fitzpatrick, A. Hopkins (ed). Measurement of patients' satisfaction with their care. London: Royal College of Physicians of London; 1993.

5. Kersnik J. An evaluation of patient satisfaction with family practice care in Slovenia. Int J Qual Health Care. 2000;12(2):143-7.

6. Polluste K, Kalda R, Lember M. Satisfaction with the access to the health services of the people with chronic conditions in Estonia. Health Policy. 2007;82:51-61.

7. Marcinowicz L, Konstantynowicz J, Chlabicz S. The patient's view of the acceptability of the primary care in Poland. Int J Qual Health Care. 2008;20:277-83.

8. Klemenc-Ketis Z, Petek D, Kersnik J. Association between family doctors' practices characterstics and patient evaluation of care. Health Policy. 2012;106:269-75

9. Senic V, Marinkovic V. Patient care, satisfaction and service quality in health care. Int J Consumer Studies. 2013;37(3):312-9.

10. Bowling A. Research methods in health. Investigating health and health services. 2nd ed. Buckingham, Philadelphia: Open University Press; 2002. p. 279.

11. Oppenheim AN. Questionnaire Design, Interviewing and Attitude Measurement. Poznan: Zysk i S-ka Wydawnictwo; 2004. p. 299-319.

12. Coulter A, Magee H. (eds). The European patient of the future. New York: Open University Press; 2003.

13. Davies E, Cleary PD. Hearing the patient's voice? Factors affecting the use of patient survey data in quality improvement. Qual Safety in Health Care. 2005;14:428-32.

\section{Corresponding author}

Ludmila Marcinowicz

4B Mieszko I Str., 15-054 Białystok

Fax: +48 857-327-848;

E-mail: ludmila.marcinowicz@umb.edu.pl 